\title{
Anna KRÝSOVÁ
}

ORCID: 0000-0002-0163-5767

Univerzita Karlova v Praze

\section{Esthetische verschuivingen in contemporaine literatuur en hun methodologische principes ${ }^{*}$}

\begin{abstract}
This article maps out the prevalent trends in publications about contemporary literature and culture with regard to their methodological grounding. It distinguishes three methodological principles (periodisation, heuristics and contextualisation) available to contemporary literary theorists who are trying to come to terms with the cultural shift they are a part of and are influenced by. A large number of publications examined for this article uses periodisation as an underlying methodological principle. The article discusses the consequences that this has for the idea and image of contemporary literature presented in these publications. Attention is paid to the critique of the use of periodisation as well as to two specific concepts proposed for the analysis of contemporary literature. Both these concepts (poetics of politics and affective dominant) are rooted in contextualisation, especially with regard to politics, but they differ in their use of the periodising framework.
\end{abstract}

Keywords: the end of postmodernism, heuristics, periodisation, poetics of politics, affective dominant.

\section{Inleiding}

Dit artikel beschrijft verschillende visies op esthetische verschuivingen in contemporaine cultuur. Tijdens mijn onderzoek naar contemporaine Nederlandstalige literatuur heb ik een corpus van beschouwingen verzameld waarin de literatuur steeds gekarakteriseerd wordt door één principe. De aanleiding om de vaak aangekondigde esthetische verschuiving te beschrijven was de volgende twijfel uitgedrukt door Terence de Toy, de auteur van een van de werken in mijn corpus:

* This article has been published with the financial support from a grant provided by the Charles University Grant Agency no. 88120, called 'Beyond postmodernism: oscillation and emancipation in contemporary Dutch novels', affiliated with Faculty of Arts, Charles University. 
"It seems as though more scholars are convinced that "postmodernism is dead" is a consensus view than actually think postmodernism is dead" (De Toy 2015: 23). De werkwoorden die in het citaat van De Toy onzekerheid lijken uit te drukken, hebben mij aangespoord om zijn bewering rondom consensus te onderzoeken en de stellingname in de "overlijdensberichten van het postmodernisme" precies te beschrijven. Door de benadrukking van de consensuele opvatting omtrent de dood van postmodernisme in dit citaat, werd mijn aandacht gevestigd op het benoemen van het onderliggende principe dat de consensus stuurt.

Behalve het onderliggende principe delen de werken in mijn corpus ook een analytische verhouding tot de contemporaine literatuur, namelijk een ambitie om te historiseren. ${ }^{1}$ Dat wil zeggen dat ze de ons onmiddelijk omgevende en vormende cultuur analytisch beschrijven alsof het om geschiedenis ging. De opgave om de contemporaine cultuur die zich rondom ons allemaal afspeelt en ontwikkelt te duiden is niet makkelijk, omdat de deelnemers aan de cultuur (die de cultuur vormen en tegelijkertijd erdoor gevormd worden) de nodige afstand ontbreekt. De afstand is een van de voorwaarden voor literaire historiografie.

Daarom moeten de auteurs van bijdrages over contemporaine literatuur zich tot het probleem verhouden dat Fredric Jameson in Postmodernism, Or The Cultural Logic of Late Capitalism als volgt verwoordt: "a view of present history as sheer heterogeneity, random difference, a coexistence of a host of distinct forces whose effectivity is undecidable" (Jameson 1991: 6). Hij spreekt daarom over de behoefte aan een verankerend principe, op basis waarvan de fenomenen van cultuur, die zich op een onmiddelijke manier met een nivellerende werking voordoen, gestructureerd kunnen worden. De historisering van het contemporaine, een doel van de bijdrages binnen mijn corpus, geschiedt op basis van periodisering. Het gebruik van een periodiserend kader is het verankerende principe in deze werken. ${ }^{2}$ De contemporaine literatuur wordt erin beschreven in contrast tot postmoderne literatuur. Wat de "overlijdensberichten van het postmodernisme" verder karakteriseert, is dat ze de hypothese onderzoeken of dat ze vanuit de veronderstelling vertrekken dat postmodernisme beëindigd is. Het denken in termen van "a grand epochal transition" (Toth 2010: 2) en het einde van een periode laat het gebruik van een periodiserend kader als een onderliggend methodologisch principe zien.

${ }^{1}$ Deze term wordt gebruikt door Sebastian Herrmann, Katja Kanzler en Stefan Schubert in hun artikel "Historicization without Periodization: Post-postmodernism and the Poetics of politics". Hun kritiek op een aantal periodiserende werken over contemporaine literatuur en cultuur (sommige met een literair-kritisch, anderen met een meer literair-historisch accent) vormt een belangrijke inspiratiebron voor mijn bijdrage.

${ }^{2}$ In de rest van het artikel verwijs ik naar mijn corpus van secundaire werken met de term "overlijdensberichten van het postmodernisme", omdat zij het einde van het postmodernisme aankondigen, wat het gebruik van een periodiserend kader verraadt. Het gaat om een vertaling van de Engelstalige term “obituaries of postmodernism” gebruikt door Irmtraud Huber (2014: 255). 
Het periodiserende kader is echter niet het enige onderliggende methodologische principe dat literatuurgeschiedschrijving ${ }^{3}$ kan sturen. Een ander principe waardoor de "sheer heterogeneity" (Jameson 1991: 6) van literaire productie verankerd kan worden, richt zich op literatuur en haar tekstuele kenmerken. Deze aanpak wordt heuristiek genoemd naar het voorbeeld van Bart Vervaecks Het postmodernisme in de Nederlandse en Vlaamse roman, waarin postmodernisme en modernisme een "heuristische term" (Vervaeck 2007: 8) genoemd worden. Binnen deze methodologie, die als de tegenpool van periodisering kan gelden, wordt het idee van ontwikkeling in literatuurgeschiedenis van de kenmerken van literaire productie binnen die periode gescheiden. Zowel periodisering als heuristiek zoeken de verankering voor hun beschrijvingen van literatuur in principes die met literatuurgeschiedschrijving of met tekstuele kenmerken van literatuur te maken hebben. In dat opzicht verschillen ze van het verankerende principe voorgesteld door Jameson. Bij hem gaat het om verwijzingen naar de culturele, politieke en economische context buiten de literaire tekst of historiografie, waarnaar hij verwijst als "some general sense of a cultural dominant" (Jameson 1991: 6). De verwijzing naar cultural dominant is van belang voor het betoog in dit artikel, omdat beide van de nader besproken aanpakken voor de interpretatie van contemporaine literatuur de methodologische verankering precies in deze vermelding van buitenliteraire, vooral politieke, context zoekt. Het gaat om de voorstellen van ten eerste Sebastian Herrmann, Katja Kanzler en Stefan Schubert, en ten tweede van Hans Demeyer en Sven Vitse om contemporaine literatuur door middel van het concept poetics of politics en affectieve dominant te lezen.

In dit artikel laat ik zien dat de werken in mijn corpus het periodiserende kader als een structurerend methodologisch principe gebruiken voor hun beschrijving van contemporaine literaire productie. Ik geef ook kort aan welke effecten en gevolgen dat teweegbrengt. Daarna ga ik in op de kritiek van het gebruik van een periodiserend kader in het artikel van Herrmann, Kanzler en Schubert "Historicization without Periodization: Post-postmodernism and the Poetics of politics". Tenslotte vergelijk ik het concept affectieve dominant (een voorbeeld van een concept voor de interpretatie van contemporaine literatuur uit mijn corpus) met het concept poetics of politics op basis waarvan Herrmann e.a. contemporaine literatuur willen lezen. Zowel de affectieve dominant als poetics of politics verwijzen vaak naar politiek; het eerste concept door kritiek op neoliberalisme en het tweede door een interpretatie van contemporaine literatuur gericht op het raakvlak tussen "politicality of texts and the poeticality of politics" (Herrmann e.a. 2016: 5).

3 Ik beschouw de "overlijdensberichten van het postmodernisme" als bijdrages tot literatuurgeschiedschrijving, ook al is hun omvang en tijdspanne niet vergelijkbaar met die van de meeste literatuurgeschiedenissen. Wat zij echter met literatuurgeschiedenissen delen, is de ambitie om esthetische verschuivingen te beschrijven en grote lijnen aan te wijzen. 
Het belangrijkste verschil tussen beide aanpakken is dat de affectieve dominant periodiseert terwijl poetics of politics slechts historiseert.

Het corpus van "overlijdensberichten van het postmodernisme" wordt samengesteld uit werken over contemporaine literatuur die het contemporaine moment proberen te historiseren. De stellingname in deze werken kan samengevat worden langs de lijnen van de vraag "is postmodernisme voorbij", dat als startpunt voor de beschrijving van eenentwintigste-eeuwse literatuur gebruikt wordt. Hiermee vertonen zij een hoge mate van periodisering in hun poging om het contemporaine te historiseren. Het corpus bestaat uit negentien boeken en artikelen waarin het periodiserende kader van beslissend belang is voor de karakterisering van het contemporaine. Voor de duidelijkheid worden alle auteurs in de volgende tabel vermeld:

Corpus van "overlijdensberichten van het postmodernisme"

Van den Akker en Vermeulen (2010 en 2017), Demeyer en Vitse (2018), Doyle (2018), Eshelman (2008), Gibbons (2015), Hoberek (2007), Holland (2013), Huber (2014), Hutcheon (2002), Nealon (2012), Greenwald Smith (2015), Vaessens (2009 en 2011), Vaessens en Van Dijk (2011), de Toy (2015), Toth (2010), Timmer (2010), Zimmerman (2004)

Tabel. Overzicht van geraadpleegde werken met een periodiserende kader

\section{Kenmerken van "overlijdensberichten van het postmodernisme"}

De "overlijdensberichten van het postmodernisme" karakteriseer ik kort aan de hand van een antal gemeenschappelijke elementen die in deze groep publicaties met het gebruik van het periodiserende kader samenhangen. De volgende drie karakteristieken van contemporaine literatuur zijn terug te zien bij meerdere auteurs: 1. Continuïteiten tussen postmodernisme en het contemporaine moment, 2. Terugkeer naar humanisme en 3. Verschuiving van aandacht eerder dan breuk. Het meest voorkomende kenmerk is de eerste; continuïteiten verschijnen in acht werken uit het corpus. De interactie tussen het contemporaine en postmodernisme wordt beschreven door middel van een nadruk op de continuïteit met de vorige periode. Bij deze drie kenmerken waarmee de auteurs van werken uit mijn corpus contemporaine literatuur proberen te beschrijven, valt de beslissende invloed en de centrale rol van postmodernisme op. Het feit dat postmodernisme zulke centrale rol speelt en dat er steeds naar verwezen wordt, hangt samen met het verankerende principe van literaire geschiedschrijving: het periodiserende kader.

In sommige "overlijdensberichten" wordt hierdoor de indruk gecreëerd dat de continuïteiten met postmodernisme noodzakelijk en inherent zijn aan de aard 
van de esthetische verschuiving die de theoretici aan het observeren zijn. Omdat de werken een nieuw paradigma proberen te formuleren, vormt postmodernisme het laatste vaste punt op de horizon waartoe zich de beschrijvingen van contemporaine literatuur, met ambities om de ontwikkeling van de laatste twintig jaar te karakteriseren, moeten verhouden. De continuïteit wordt zelden duidelijk en precies geïdentificeerd. Uitspraken zoals de volgende komen in werken van de auteurs in deze groep vaak voor: "We do not wish to suggest that all postmodern tendencies are over and done with. But we do believe many of them are taking another shape, and, more importantly, a new sens, a new meaning and direction" (Van den Akker \& Vermeulen 2010: 4). Raoul Eshelman kleedt deze gedachte in in vergelijkbaar vage termen: "All performatist works feed in some way on postmodernism; some break with it markedly, while others retain typical devices but use them with an entirely different aim" (Eshelman 2008: xiv). Het periodiserende kader dwingt deze theoretici om de contemporaine literatuur op deze manier te begrenzen en vergelijken, maar het lukt hen zelden om de continuïteit te specificeren voordat ze aan de analyse van de werken zelf toe komen.

Het contemporaine is volgens Mary K. Holland (2013), Jens Zimmerman (2004) en Thomas Vaessens (2011) gekarakteriseerd op basis van een filosofische aanvulling die contrasteert met postmodernisme. Wederom werpt postmodernisme dus een lange schaduw en tegelijkertijd fungeert het als een negatieve identificator op basis waarvan contemporaine literatuur beschreven kan worden. De filosofische aanvulling van contemporaine literatuur waarover bij de tweede kenmerk sprake is, is humanisme. Holland, Zimmerman en Vaessens veronderstellen dat theorie en postmodernisme (termen die zij als onderling inwisselbaar gebruiken) zich kritisch opgesteld hebben tegenover humanisme. Een citaat uit Vaessens is representatief voor de positie van hen alle drie: "Postmodernism, [...] started as a reaction against the liberal humanist (and structuralist) suppression of [...] aspects in the definition of art as eternal and universal" (Vaessens 2011: 6). Holland gaat nog verder dan de andere theoretici, omdat zij postmoderne literatuur zelfs antihumanistisch noemt: "[...] we tend to read late twentieth-century literature as essentially antihumanistic, and with all the distaste that such a term implies" (Holland 2013: 2). Vaessens, Zimmerman en Holland beseffen dat postmodernisme grote klappen heeft uitgedeeld aan de humanistische ideologie (om het zo breed mogelijk te definiëren) en beschrijven contemporaine literatuur of theorie als gekenmerkt door de gezuiverde en verschoonde waarden van humanisme. Na de vurige kritiek van postmodernisme wordt humanisme in hun visie van zijn universaliserende tendensen ontdaan, terwijl zij de constructieve aspecten van humanisme benadrukken en opnieuw interpreteren. Deze terugkeer illustreert een principe van literatuurgeschiedschrijving: om een literaire ontwikkeling te kunnen beschrijven, is het nodig om een sterk contrasterend element aan te wijzen. 
Sommige auteurs in mijn corpus lijken zich bewust te zijn van de gevaren van periodisering en zij benadrukken de geleidelijke aard van de literatuurhistorische verandering die zij in contemporaine literatuur ten opzichte van postmoderne literatuur aan het observeren zijn. Het derde kenmerk, namelijk verschuiving eerder dan breuk, lijkt in de werken over contemporaine literatuur deze functie te vervullen. Hoberek (2007) en Huber (2014) gaan het voorzichtigst en het meest genuanceerd te werk in hun gebruik van het idee van het einde van postmodernisme, in een poging om de nadruk op innovatie, die kenmerkend is voor een beschrijving van esthetische verandering, te temperen. Hobereks karakterisering van contemporaine Amerikaanse literatuur, die hij met het idee van het einde van postmodernisme inleidt, eindigt met een oproep aan andere literatuurwetenschappers om zich niet te laten verleiden tot periodisatie: "the proper response to this shift consists neither of assertions of postmodernism's continued relevance nor of sweeping declarations of a potential successor but rather of concrete analyses of literary form and the historical conditions that shape it" (Hoberek 2007: 240). Hoberek spreekt over een verschuiving in contemporaine cultuur met een nadruk op de langzame en geleidelijke aard ervan. Elders zegt hij dat "cultural sea changes [...] appear first in processes of gradual, uneven, cellular transformation" (Hoberek 2007: 239). Het periodiserende kader stuurt dus de manier waarop contemporaine literatuur beschreven wordt op het niveau van thema's en kenmerken (humanisme, continuïteit met postmodernisme), maar ook op het gebied van de beschrijving van de esthetische verschuiving.

\section{Kritiek op het periodiserende kader}

Herrmann e.a. verwoorden de kritiek op het periodiserende kader in drie punten die zich verhouden tot de drie kenmerken van de "overlijdensberichten van het postmodernisme". Het eerste kenmerk, continuïteit, helpt om de scherp getrokken grenzen tussen de postmoderne en contemporaine literatuur wel te doorbreken, maar tegelijkertijd construeert het denken in termen van het einde een mogelijk valse dichotomie. Herrmann e.a. drukken het als volgt uit: "The framework of periodization that controls this creation myth of the contemporary moment thus entails totalizing effects [and] [...] it invests scholarship in erecting boundaries around the distinctiveness of the contemporary" (Herrmann e.a. 2016: 8). Postmodernisme wordt dus volgens Herrmann e.a. met te makkelijk contrasterende karakteristieken ten opzichte van het contemporaine beschreven en aaneengesmeed in een entiteit die nooit heeft bestaan.

Het tweede kenmerk van de terugkeer naar het humanisme is verbonden met de verschoonde waarden van humanisme, zoals ,meaning and investment in the real world" (Holland 8), die traditioneel gerepresenteerd zijn geweest in de rea- 
listische roman. Herrmann e.a. leggen uit dat de wending tot een gekwalificeerde, nieuwe soort realisme in contemporaine literatuur ontstaat door het gebruik van een periodiserend metaverhaal van "exhaustion of literary form that causes breaks between literary periods" (Herrmann e.a. 2016: 8). De theoretici zijn weer op zoek naar een contrast tussen postmodernisme en contemporaine literaire productie met "societal referentiality" (Herrmann e.a. 2016: 7) die, vanwege het periodiserende kader, gecontrasteerd wordt met de veronderstelde naar binnen gekeerde blik van postmoderne teksten ,interested in representing representation" (Herrmann e.a. 2016: 10). Met de terugkeer naar humanisme hangt ook "a deeply ambivalent longing for a presumed 'state of innocence' $[\ldots]$ that $[\ldots]$ does not exist" (Herrmann e.a. 2016: 10) samen. De ambivalentie valt te bespeuren zowel bij Holland als bij Zimmerman, die beseffen dat de universaliserende aspecten van humanisme problematisch zijn. Realisme "inflected via an additional adjective or prefix" (Herrmann e.a. 2016: 8) opgevat als een esthetische, literaire reactie op de theoretisch geobserveerde ontwikkelingen, wordt door Vaessens, Zimmerman en Holland niet voorgesteld als het hoofdkenmerk van contemporaine literatuur. Dit kan veroorzaakt worden door het feit dat mijn corpus van overlijdensberichten en dat van Herrmann e.a. slechts gedeeltelijk overeenkomt. Binnen mijn corpus is het Huber die zich het meest met een "nieuw" realisme opgevat als een reactie op postmodernisme bezighoudt.

Het derde kritische punt hangt samen met de verbinding tussen eenentwintigste-eeuwse technologische en mediale ontwikkelingen en de esthetische reactie erop. Het probleem ontstaat volgens Herrmann e.a. al bij het leggen van een causaal verband tussen esthetiek en media: zij verzetten zich tegen de "mechanistic manner" (Herrmann e.a. 2016: 11) waarmee de ontwikkelingen in ,the 'superstructure' of culture follow from changes in the technological and medial "base" (Herrmann e.a. 2016: 11). De relatie die de periodiserende theoretici leggen tussen base en superstructure (die door Herrmann e.a. uitgediept wordt door middel van een voorbeeld van een verband tussen literaire en televisieproductie) is volgens de Duitse theoretici te eenvoudig en te eenzijdig. Precies deze nadruk zien wij bij Hoberek, die beweert dat "culture itself had appropriated the aesthetics of postmodernism, which - now playing monotonously on everyone's television and computer screens - turned out to be as reproducible as its creators had contemptuously said all previous art was" (Hoberek 2007: 233). De kritiek van de vertekeningen die het gebruik van een periodiserend kader teweegbrengt is daarentegen niet van toepassing op Hobereks "Introduction: After Postmodernism" als geheel. In weerwil van het feit dat hij begint met een overweging van het einde van het postmodernisme, waarschuwt hij zelf tegen enkele valkuilen van periodisering die de analyse en beschrijving van contemporaine literatuur moeten vermijden. 


\section{Vergelijking van poetics of politics en de affectieve dominant}

In de volgende alinea's worden twee concrete voorstellen voor de interpretatie van contemporaine literatuur; poetics of politics en affectieve dominant nader besproken. Herrmann, Kanzler en Schubert stellen in plaats van het gebruik van het grootse periodiserende kader een lokale aanpak voor die de historisering van het contemporaine mogelijk maakt. Wat het contemporaine moment waarop "particular historical dynamisms surface" (Herrmann e.a. 2016: 4) karakteriseert, is het raakvlak tussen poëtica en politiek waaraan hedendaagse literatuur aandacht besteedt. Deze aanpak staat hen toe om de valkuilen van periodisering (constructie van een periode die een totaliserend effect teweegbrengt, gebruik van een metaverhaal van een uitgeputte literaire vorm, automatisch gelegd causale verband tussen literatuur en media) voor te komen, zowel op het diachrone als op het synchrone niveau. Met betrekking tot deze twee niveaus zal ik straks poetics of politics met de affectieve dominant vergelijken.

Verder stellen Herrmann e.a. dat poetics of politics historisering van het contemporaine moment toestaat, omdat het laat zien dat de literaire producten aan het begin van de eenentwinigste eeuw "(selfconsciously) engage with politics and assert their own political relevance while (selfreflexively) confronting the textual boundedness and mediation of political projects and their effects" (Herrmann e.a. 2016: 5). Zij sluiten hun voorstel voor een historiserende aanpak met de volgende woorden af: "the poetics of politics illuminates a quality of the contemporary moment that becomes characteristic through its very heterogeneity" (Herrmann e.a. 2016: 5). De auteurs beschouwen deze karakteristiek van hun concept als een aanbeveling en een welkome oplossing voor de problemen van periodisatie. Zij zoeken hun heil niet in de heuristische methodologie, omdat die een wijdverbreid en algemeen herkenbaar label nodig heeft dat vervolgens van een tijdsperiode gescheiden kan worden. Voor de beschrijving van een emergente, zich geleidelijk ontwikkelende esthetische verschuiving biedt heuristiek weinig steun.

Het voorstel van poetics of politics als concept wordt ingeleid door een discussie over de problemen van periodisering met verwijzing naar Jamesons oplossing: het gebruik van het concept van cultural dominant. In de voetnoten merken Herrmann e.a. op dat "Jameson himself proposes the concept of the 'cultural dominant' as an alternative to the bounded and totalizing notion of the period" (Herrmann e.a. 2016: 4). De poetics of politics aanpak heeft volgens mij echter nog meer gemeen met cultural dominant dan Herrmann e.a. laten zien. Een culturele dominant zoals postmodernisme wordt namelijk niet alleen gedefinieerd als een oplossing voor het problematische concept van periode (zoals Herrmann e.a. 2016) benadrukken, maar ook door het perspectief op culturele productie als onderdeel van alle andere soorten productie: "aesthetic production today has become integrated into 
commodity production generally" (Jameson 1991: 4). Zoals de titel van Jamesons boek Postmodernism, or, the Cultural Logic of Late Capitalism al aangeeft, wordt postmodernisme als culturele dominant veel meer gedefinieerd door de verhouding tot economische en politieke factoren, eerder dan door de strikt literaire principes zoals periodisering. Aan de benadrukking van dit aspect van Jamesons gedachtegoed had een door buitenliteraire verankering gedefinieerde aanpak zoals poetics of politics veel meer gehad dan aan de verwijzing naar periodisering.

Poetics of politics is in methodologisch opzicht namelijk veel meer gedefinieerd door een relatie met het buitenliteraire fenomeen ,intersections of intertextuality and politicality" (Herrmann e.a. 2016: 4), waardoor Herrman, Kanzler en Schubert naar ,a renewed interest in addressing issues of social concern” in contemporaine romans verwijzen. In plaats van erover te spreken in termen van literatuur (bijvoorbeeld als over „nieuw” realisme), kiezen zij ervoor om direct naar politiek te verwijzen, maar dan in een gekwalificeerde zin: "The field of electoral politics is only one among several political contexts that have recently hosted (self-conscious) reflections on the narrative construction and constructedness of the issues that are communicated there" (Herrmann e.a. 2016: 5). De focus op politieke en maatschappijkritische thema's karakteriseert zowel poetics of politics als de affectieve dominant, ook al gebruikt de eerste aanpak geen periodiserend kader en de tweede wel.

Het concept van de affectieve dominant die als vertegenwoordiger van "overlijdensberichten van het postmodernisme" optreedt, wordt voorgesteld in "De affectieve dominant: een ideologiekritische lezing van recent Nederlandstalig proza" van Demeyer en Vitse ${ }^{4}$. Hun uitgangspunt neemt wel het periodiserende kader voor lief, omdat zij het hebben over de "de emergente esthetische sensibiliteit "beyond postmodernism"” (Demeyer \& Vitse 2018: 220). Hun artikel citeert een aantal recente bijdrages tot de discussie over contemporaine Nederlandstalige literatuur die rond het thema van het einde van het postmodernisme wordt gevoerd. Verder situeren ze hun artikel nog in de bredere context van "het bloeiende internationale, veelal Angelsaksische georiënteerde debat over de literatuur na het postmodernisme, waarbij de Nederlandstalige discussie aansluit." (Demeyer \& Vitse 2018: 222). Het zou erop kunnen lijken dat Demeyer en Vitse zich alleen maar aansluiten bij eerder gevoerde debatten en dat ze daarmee het periodiserende kader met al zijn problemen ook overnemen. Het concept van de affectieve dominant, die hun analyse van contemporaine romans stuurt, reflecteert echter op de valkuilen van periodisering en vermijdt ze.

${ }^{4}$ Dezelfde methodologische uitgangspunten met betrekking tot de periodiserende kader bevat ook het in 2021 verschenen boek van Demeyer en Vitse, Affectieve crisis, literair herstel. Het politieke engagement van de wetenschappers en de resultaten van hun onderzoek naar millenialromans, die betrekking hebben op het eenentwintigste-eeuwse politieke en collectieve leven, komen in dit boek nog nadrukkelijk naar voren dan in het artikel uit 2018. 
Net als Herrmann, Kanzler en Schubert bespreken Demeyer en Vitse in hun uitwerking van het concept de synchrone en diachrone aspecten ervan. Dit citaat begint met de inleiding van het punt waarop hun aanpak verschilt van de tot nu toe besproken "overlijdensberichten van het postmodernisme": 5

We presenteren een hypothese die aansluit bij de hierboven besproken benaderingen, maar die de verhouding tussen de postmoderne en hedendaagse roman op een alternatieve manier conceptualiseert. Daarvoor grijpen we terug op het dominantbegrip uit het Russische formalisme en uit het werk van Brian McHale (1987). Die laat ons toe om de hedendaagse literatuur diachroon te bestuderen in relatie tot het postmodernisme, maar tevens om de synchrone relatie tussen deze literatuur en haar context op een ideologiekritische manier te benaderen (Demeyer \& Vitse 2018: 223).

Omdat ze de verhouding tussen contemporaine en postmoderne roman als een verschuiving van de dominant zien, gebruiken Demeyer en Vitse aan de ene kant wel de dichotomie postmodern vs. contemporain die van de diverse culturele productie tijdens beide perioden een homogene voorstelling maakt. Aan de andere kant stelt het gebruik van de dominant (vooral de versie van $\mathrm{McHale}$ ) hen ertoe in staat om te beschrijven "how one set of literary forms emerges from a historically prior set of forms" (McHale 1987: 5-6). Dit dynamische model laat de literaire ontwikkeling zien in zijn dynamiek, een kenmerk waarin de dominant overeenkomt met het kenmerk van verschuiving dat bij Hoberek te zien was en beantwoordt ook aan de uitnodiging van Herrmann e.a. om te laten zien welke "historical dynamisms" (Herrmann e.a. 2016: 4) naar voren treden.

Zowel affectieve dominant als poetics of politics duiden hun werking zowel in een synchroon als een diachroon opzicht aan. Het verschil tussen het gebruik van deze twee niveaus van analyse is dat poetics of politics als concept voor de analyse van literatuur niet veel grip biedt op het diachrone aspect: de vergelijking tussen de opkomende en historische tekstuele vormen staat in deze benadering niet centraal. Contemporaine literatuur moet volgens Herrmann e.a. niet vergeleken worden met de postmoderne, omdat dat "reductive reformulations of the periods" (Herrmann e.a. 2016: 4) veroorzaakt. Vitse en Demeyer gaan de bestudering van contemporaine literatuur in relatie tot de postmoderne echter niet uit de weg. Wat het synchrone niveau betreft, vullen zij de verhouding tussen literatuur en haar context ideologiekritisch aan. Hun kritiek focust op de neoliberale ideologie waar in de literatuur naar verwezen wordt. Herrmann e.a. willen zich op het synchrone niveau verhouden tot de "politicality of texts and the poeticality of politics" (Herrmann e.a. 2016: 5) waarbij politiek breder gedefinieerd wordt dan datgene wat in directe verbinding staat met politieke instituties.

5 De "overlijdensberichten" vermeld in Demeyer en Vitses artikel komen gedeeltelijk overeen met een aantal van werken in mijn corpus, Huber (2014), Vaessens en Van Dijk (2011) en Timmer (2011). 


\section{Conclusie}

Dit artikel beschreef de methodologische principes die ingezet worden bij onderzoeken naar contemporaine literatuur. Geconfronteerd met de gevarieerdheid, enorme hoeveelheid en zich gelijktijdig ontwikkelende literaire productie zoeken de theoretici naar een structurerend principe dat hen in staat stelt om contemporaine literatuur te beschrijven. Dit onderliggend principe wordt in het corpus van "overlijdensberichten van het postmodernisme" als het periodiserende kader aangeduid. Een methodologische tegenpool van periodisering is heuristiek waar echter geen van de hier besproken theoretische teksten voor kiest. Een reden daarvoor zou kunnen zijn dat de esthetische verschuiving nog niet ver genoeg van het laatst algemeen geaccepteerd heuristisch label (namelijk postmodernisme) is doortrokken. De verwijzing naar buitenliteraire fenomenen (ontwikkelingen op het gebied van politiek of economie) biedt een andere mogelijkheid voor verankering van een beschrijving van contemporaine literatuur. De twee nader besproken aanpakken, de affectieve dominant en poetics of politics, worden allebei gedeeltelijk gedefinieerd door de verbindingen die zij leggen tussen contemporaine literatuur en haar maatschappelijke en politieke context. Zij verschillen van elkaar echter op het gebied van het gebruik van het periodiserende kader.

Herrmann, Kanzler en Schubert weigeren het periodiserende kader te gebruiken, waardoor poetics of politics als benadering minder geschikt wordt voor onderzoekers met een ambitie om de literair-historische dynamiek te beschrijven. Demeyer en Vitse sluiten zich bij de opvattingen van andere "overlijdensberichten" aan, zonder in een vertekenende en homogeniserende karakterisering van literaire productie binnen bepaalde periodes te vervallen. Tegelijkertijd biedt de affectieve dominant de kans om contemporaine literatuur in een flexibel en dynamisch model te beschrijven, dat net als poetics of politics ruimte schept voor een synchrone focus op politiek of ideologiekritiek. Beide aanpakken bieden genoeg steun voor de beschrijving van een alsnog onduidelijke opkomende contemporaine esthetica die aan het evolueren is.

\section{Bibliografie}

Akker, Robin van den, \& Timotheus Vermeulen (2010): "Notes on Metamodernism". Notes on Metamodernism, Journal of Aesthetics \& Culture 2:1, 1-14.

Akker, Robin van den, e.a. (2017): Metamodernism Historicity, Affect, Depth after Postmodernism. London: Rowman and Littlefield International.

Demeyer, Hans, \& Sven Vitse (2018): "De affectieve dominant: een ideologiekritische lezing van recent Nederlandstalig proza". Tijdschrift voor Nederlandse Taal- en Letterkunde 134:3, 220 244.

Demeyer, Hans, \& Sven Vitse (2021): Affectieve crisis, literair herstel: De romans van de millennialgeneratie. Amsterdam: Amsterdam University Press. 
Doyle, Jon (2018): "The changing face of post-postmodern fiction: Irony, sincerity, and populism". Critique: Studies in Contemporary Fiction 59:3, 259-270.

Eshelman, Raoul (2008): Performatism, or the End of Postmodernism. Aurora, Colorado: The Davies Group Publishers.

Gibbons, Alison (2015): “'Take That You Intellectuals!' and 'kaPOW!': Adam Thirlwell and the Metamodernist Future of Style”. Studia Neophilologica 87. Sup1, 1-15.

Holland, Mary K. (2013): Succeeding Postmodernism: Language and Humanism in Contemporary American Literature. London: Bloomsbury Academic.

Hoberek, Andrew (2007): “Introduction: After Postmodernism”. Twentieth Century Literature 53:3, 233-247.

Herrmann, Sebastian M., e.a. (2016): "Historicization without Periodization: Post-Postmodernism and the Poetics of politics", laatst geraadpleegd op 23.09.2019<https://nbn-resolving.org/ urn:nbn:de:bsz:15-qucosa-207652>.

Huber, Irmtraud (2014): Literature after Postmodernism: Reconstructive Fantasies. New York, NY: Palgrave Macmillan.

Hutcheon, Linda (2002): The Politics of Postmodernism. London: Routledge.

Jameson, Fredric (1991): Postmodernism, Or, the Cultural Logic of Late Capitalism. London/New York: Verso.

McHale, Brian (1987): Postmodernist Fiction. New York: Methuen.

Nealon, Jeffrey T. (2012): Post-Postmodernism or, The Cultural Logic of Just-in-Time Capitalism. Palo Alto: Stanford University Press.

Smith, Rachel Greenwald (2015): Affect and American Literature in the Age of Neoliberalism. New York, NY: Cambridge University Press.

Timmer, Nicoline (2010): Do You Feel It Too? The Post-postmodern Syndrome in American Fiction at the Turn of the Millennium. Amsterdam: Rodopi.

Toth, Josh (2010): The Passing of Postmodernism: A Spectroanalysis of the Contemporary. Albany, New York: SUNY Press.

Toy de, Terence (2015): It's All in The Family: Metamodernism and the Contemporary (Anglo-)American Novel. Ann Arbor, Michigan: ProQuest LLC.

Vaessens, Thomas, \& Yra van Dijk (2011): Reconsidering the Postmodern: European Literature beyond Relativism. Amsterdam: Amsterdam University Press.

Vaessens, Thomas (2011): "Dutch novelists beyond 'postmodern' relativism". Journal of Dutch Literature 2:1, 5-34.

Vervaeck, Bart (2007): Het postmodernisme in de Nederlandse en Vlaamse roman. Nijmegen/Mechelen: Uitgeverij Vantilt.

Zimmermann, Jens (2004): "Quo Vadis: Literary Theory beyond Postmodernism”. Christianity and Literature. 53:4, 495-519.

Neerlandica Wratislaviensia 30, 2020

(C) for this edition by CNS 